\title{
PERANCANGAN SISTEM INFORMASI PENJUALAN ONLINE BERBASIS WEB PADA BATIK WIDI NUGRAHA NGAWI
}

\author{
Nur A Febriyati ${ }^{1}$, M. Yusuf Arnol ${ }^{2}$ \\ ${ }^{1,2}$ Universitas 45 Surabaya \\ Email: nurahlinaf@univ45sby.ac.id ${ }^{1}$,yusuf.arnold@gmail.com ${ }^{2}$
}

(Naskah masuk: 11 Oktober 2020, diterima untuk diterbitkan: 29 Oktober 2020)

\begin{abstract}
Abstrak
Salah satu rumah industri batik yang terkenal di kota Ngawi, Jawa Timur yaitu Batik Widi Nugraha. Unit usaha kecil menengah ini fokus memproduksi kain batik. Sistem Penjualan yang diterapkan pada unit usaha ini masih manual, belum memungkinkan untuk memperluas area pemasaran dan menjangkau semua wilayah, serta sulitnya memperoleh informasi mengenai produk Batik Widi Nugraha. Untuk memperluas pemasaran dan penjualan produk batik, dibutuhkan sistem penjualan online berbasis website. Tujuan dari penelitian ini adalah untuk mendesain sistem informasi penjualan online berbasis website yang terintegrasi. Metodologi yang digunakan untuk perancangan dan pengembangan sistem penjualan online ini, adalah metodologi terstruktur dengan model SDLC (System Development Life Cycle). Dengan adanya sistem informasi penjualan ini, masyarakat semakin mudah untuk mencari dan mendapatkan informasi tentang Batik Widi Nugraha Ngawi berupa informasi produk yang ditawarkan dan bisa berbelanja tanpa harus ke toko. Sistem informasi ini dirancang dengan menggunakan use case diagram. Metode pengujian menggunakan Metode Black Box. Hasil pengujian menunjukkan bahwa sistem dapat diterapkan dalam bisnis Batik Widhi Nugraha agar lebih berkembang dan meningkatkan hasil pendapatan penjualan, serta dapat berdampak pada peningkatan pelayanan pelanggan (konsumen) dan pengelolaan administrasi.
\end{abstract}

Kata Kunci: Perancangan, Sistem Informasi, Penjualan Online, Batik Widi Nugraha

\section{DESIGN SALES INFORMATION SYSTEM ONLINE BASED ON WEB ON BATIK WIDI NUGRAHA NGAWI}

\begin{abstract}
One of the famous batik industrial houses in the city of Ngawi, East Java, is Batik Widi Nugraha. This small and medium business unit focuses on producing batik cloth. The sales system applied to this business unit is still manual, it is not possible to expand the marketing area and reach all areas, and the difficulty of obtaining information about Widi Nugraha's Batik products. To expand marketing and sales of batik products, sales system is needed online a-based website. The purpose of this research is to designsales information system online -based website an integrated. The methodology used for the design and development of this online sales system is a structured methodology with the SDLC (modelSystem Development Life Cycle). With this sales information system, it is easier for people to find and get information about Widi Nugraha Ngawi Batik in the form of product information offered and they can shop without having to go to the store. This information system is designed using a use case diagram. The test method uses the Method Black Box. The test results show that the system can be applied in Batik Widhi Nugraha's business to be more developed and increase sales revenue and can have an impact on improving customer service (consumers) and administration management.
\end{abstract}

Keywords: Design, Systems Information, Sales of Online, Batik Widi Nugraha

\section{ENDAHULUAN}

Teknologi informasi era milenial saat ini berkembang pesat. Para pelaku bisnis dan pengusaha memanfaatkan teknologi informasi untuk mempermudah usaha mereka. Perkembangan ini juga telah mengubah model pemasaran, dan penggunaan internet menjadi pilihan utama dalam memasarkan 
produk perusahaan. Internet dipandang sebagai cara untuk memperoleh dan berbagi informasi dengan cepat dan mudah, dan dimanfaatkan oleh para pelaku bisnis sebagai alat untuk mempromosikan produk mereka. Selain itu, Internet telah mempromosikan gaya hidup masyarakat untuk memenuhi kebutuhan sehari-hari, dan memasarkan produk[1]. Penjualan Online berbasis web merubah semua fungsi bisnis area dan setiap alur bisnis mulai dari transaksi jual beli produk dan informasi secara elektronik melalui komputer.

Electronic commerce merupakan salah satu sarana yang dapat memudahkan produsen dalam melakukan transaksi. Tidak hanya dapat memudahkan produsen untuk berkomunikasi dengan konsumen, namun kini e-commerce juga dapat memudahkan produsen dalam mengelola produk yang dijualnya. Aplikasi web dan browser internet telah banyak digunakan sebagai media bisnis antara perusahaan atau badan usaha dengan konsumen. Salah satunya adalah e-commerce. Elektronik bisnis menekankan penggunaan teknologi informasi dan komunikasi (TIK) dalam transaksi antara perusahaan dan organisasi, serta antara perusahaan dan konsumen[2].

Berbagai penelitian terkait perancangan sistem informasi penjualan online berbasis web telah banyak dilakukan sebelumnya, diantaranya penggunaan model Waterfall software engineering (RPL), bahasa pemrograman database PHP dan MySQL untuk pengembangan sistem. Hasil yang diperoleh dari penelitian ini adalah berkembangnya e-commerce dan untuk mengatasi permasalahan pemasaran yang masih berskala kecil dan mendorong penjualan produk batik.[3]. Selain itu, penelitian terkait yaitu pentingnya media informasi dalam mempromosikan batik Kulon Progo ini. Dengan pesatnya perkembangan teknologi dan informasi saat ini, telah sangat mempengaruhi penyebaran informasi industri dan pariwisata[4]. Hasil penelitian terkait lainnya adalah dengan memanfaatkan website Semarang Batik Omah sebagai media komunikasi antar produsen yang mengkhususkan diri dalam pembuatan dan pengembangan Batik Semarang. Website Omah Batik Semarangan membuat perdagangan batik Semarang lebih mudah dan efisien[5].

Batik Widi Nugraha adalah home industry yang bergerak di bidang penjualan pakaian batik. Secara tradisional, proses penjualan batik yang saat ini berjalan masih dilakukan dengan penjualan grosir dan eceran kepada konsumen. Bagian penjualan yang demikian tentunya tidak terlepas dari persaingan antar pengusaha batik. Sedangkan sistem penjualan yang saat ini diterapkan oleh Batik Widi Nugraha adalah membuka galeri batik. Hal ini menjadi salah satu keluhan dari pemilik karena tidak dapat menjangkau konsumen yang banyak, sehingga apabila transaksi antara pembeli dan penjual dalam jumlah besar, tempat usaha tidak dapat menampung seluruh konsumen karena keterbatasan tempat. Menurut pernyataan pemiliknya, tidak mungkin dilakukan perluasan kawasan karena keterbatasan ruang dimana lokasi sangat penting.

Berdasarkan permasalahan yang diuraikan maka dapat disimpulkan bahwa Batik Widhi Nugraha membutuhkan solusi dari permasalahan tersebut. Pasar perlu memperkenalkan produk batik, yaitu dengan menggunakan website dinamis sebagai cara untuk mempromosikan perkembangan usaha atau sebagai sarana untuk meningkatkan penjualan.[6]. Salah satu solusinya adalah dengan menggunakan teknologi Internet, yaitu membuat aplikasi Web berbasis e-commerce. Melalui perancangan sistem informasi -commerce berbasis web diharapkan dapat meningkatkan penjualan produk, sehingga dapat memaksimalkan dan menghasilkan laporan secara cepat, tepat dan berkualitas, serta merupakan salah satu cara untuk meningkatkan loyalitas konsumen.

\section{METODE PENELITIAN}

\subsection{Metode Pengumpulan Data}

Metode pengumpulan data yang digunakan dalam penelitian ini adalah Studi Pustaka, Studi Lapangan dan Wawancara. Studi Pustaka dilakukan dengan penelusuran pustaka seperti buku-buku, literatur dan jurnal-jurnal karya ilmiah yang relevan dengan penelitian. Studi lapangan dan wawancara dilakukan dengan cara pengamatan langsung dengan objek penelitian, penggalian informasi data analisa masalah untuk memperoleh penjelasan-penjelasan maupun informasi untuk berbagai hal yang berkaitan dengan penelitian ini.

\subsection{Metode Pengembangan Sistem}

Metode pengembangan sistem dalam penelitian ini menggunakan metode SDLC (System Development Life Cycle). Macam-macam jenis metode SDLC yang telah digunakan dan dikembangkan seperti Ada beberapa jenis System Development Life Cycle (SDLC), yaitu: Tradisional SDLC, Agile SDLC, Waterfall SDLC, Scrum SDLC,dll[7]. Metode ini menjelaskan metode sistematis dan metode sekuensial pengembangan perangkat lunak, tahapan sebagai berikut:[8]

\section{a. Tahapan Identifikasi}

Sebelum memulai pekerjaan teknis, perlu adanya komunikasi dengan pelanggan. Hasil dari komunikasi tersebut adalah inisialisasi proyek, seperti menganalisis masalah langsung dan mengumpulkan data yang diperlukan, dan membantu menentukan fungsi perangkat lunak. Data lain juga dapat dikumpulkan dari jurnal, artikel, dan internet.

\section{b. Tahap Perencanaan}


Tahap selanjutnya adalah tahap perencanaan yang menggambarkan perkiraan tugas teknis yang akan dilakukan, risiko yang mungkin terjadi, sumber daya yang dibutuhkan untuk membuat sistem, produk kerja yang akan dihasilkan, rencana kerja yang akan dijalankan, dan tahap untuk menelusuri proses kerja sistem.

\section{c. Tahapan Desain Sistem}

Tahapan ini merupakan tahap perancangan, berfokus pada perancangan struktur data, arsitektur perangkat lunak, tampilan antarmuka dan algoritma program. Tujuannya adalah untuk lebih memahami gambaran keseluruhan tentang apa yang akan dilakukan.

\section{d. Tahapan Implementasi}

Tahapan ini adalah proses mengubah bentuk desain menjadi kode atau bentuk / bahasa yang dapat dibaca mesin. Setelah pengkodean selesai, maka akan diuji pada sistem dan pada kode yang dibuat. Tujuannya untuk menemukan kesalahan yang mungkin bisa diperbaiki nanti.

\section{e. Tahapan Pengujian}

Tahapan ini merupakan tahapan mengimplementasikan perangkat lunak untuk pelanggan berdasarkan umpan balik yang diberikan, dan secara rutin melakukan perawatan perangkat lunak, perbaikan perangkat lunak, evaluasi perangkat lunak dan pengembangan perangkat lunak agar sistem dapat terus beroperasi dan berkembang sesuai fungsinya. Dalam penelitian ini penggunaan pengujian black box difokuskan pada persyaratan fungsional perangkat lunak. Dalam pengujian ini, memungkinkan pengembang perangkat lunak untuk mendapatkan sekumpulan kondisi input yang akan sepenuhnya memenuhi semua persyaratan fungsional program[9]. Pengujian ini juga pernah dilakukan oleh[10].

\section{HASIL DAN PEMBAHASAN 3.1 Perancangan Sistem}

Realisasi dalam pembuatan perancangan sistem informasi penjualan online dalam penelitian ini adalah dengan merancang sistem menggunakan UML, dan membuat sistem informasi penjualan online berbasis web dengan menggunakan bahasa pemograman PHP dan database server MySQL sebagai tempat penyimpanan back-end aplikasi $e$ commerce.

\subsection{Diagram Use Case}

Diagram use case pada perancangan sistem informasi penjualan online ini dijalankan oleh 3 partisipan (yaitu pelanggan, administrator, dan pemilik). Ketiga peserta tersebut memiliki akses sesuai fungsi masing-masing peserta, seperti gambar di bawah ini:
1. Administrator adalah peserta yang memiliki hak akses dalam mengelola data pengguna, informasi, pemesanan, pembayaran, pengiriman, dan pemrosesan laporan transaksi.

2. Pelanggan adalah pelaku yang dapat memilih, melihat dan membeli produk.

3. Pemilik toko adalah pelaku yang hanya dapat melihat dan mencetak laporan penjualan. Diagram use case untuk pemodelan akan dibuat sebagai berikut:

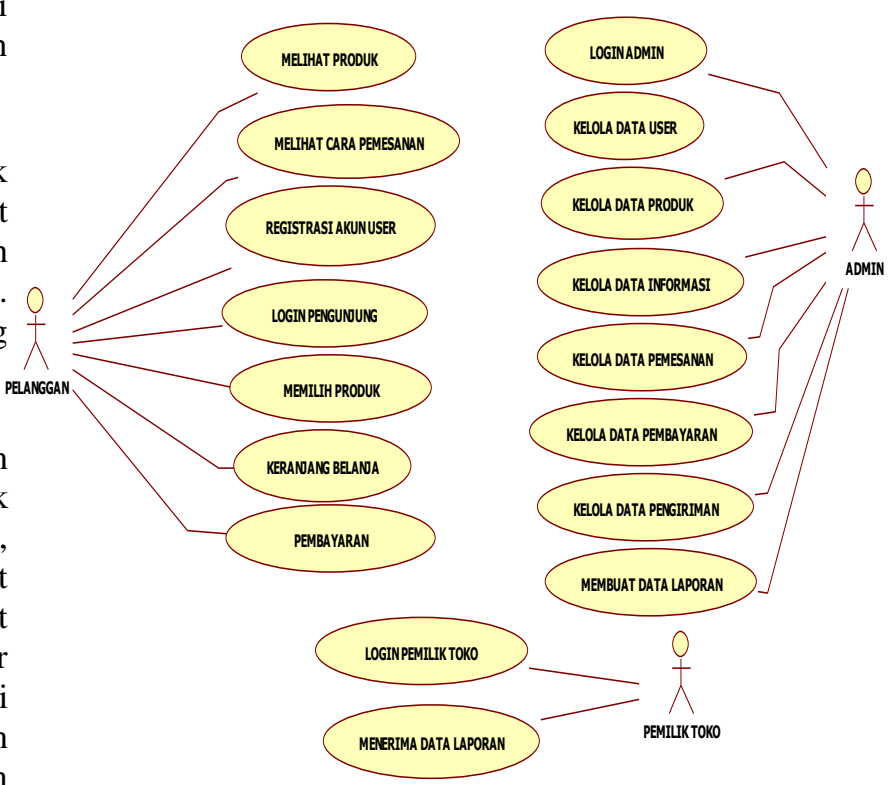

Gambar 1. Use case diagram prototype

\subsection{Desain Site Structure Diagram}

Pada tahap ini membuat site diagram untuk menggambarkan menu yang ada pada website $e$ commerce. Hal Ini bertujuan untuk mempermudah proses perancangan. Diagram menu e-commerce dapat dillihat pada Gambar 4.

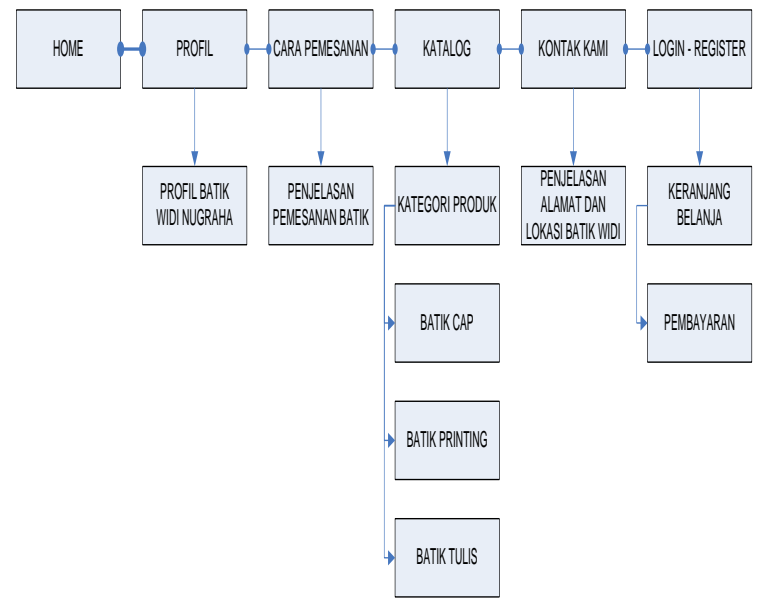

Gambar 2. Site structure diagram e-commerce 


\subsection{Tampilan Awal}

Homepage (Menu Utama) merupakan tampilan awal yang pertama kali muncul pada saat mengunjungi e-commerce Batik Widi Nugaraha. Halaman ini menampilkan seluruh konten. Gambar ini merupakan homepage tertentu dan dapat dilihat pada Gambar 3.

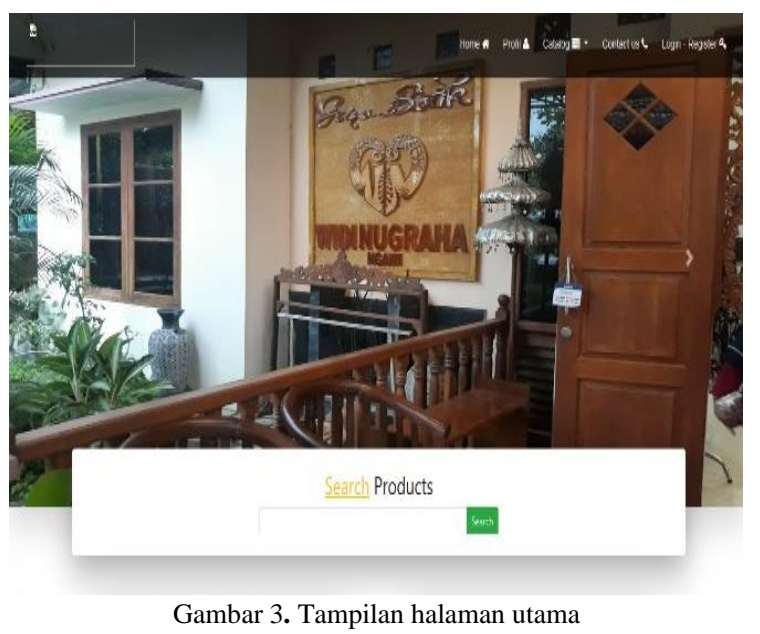

\subsection{Tampilan Halaman Katalog}

Halaman katalog berisi data batik yang telah dikelompokkan yaitu batik tulis, batik cap dan batik printing. Gambar ini adalah halaman katalog, seperti yang ditunjukkan pada Gambar 4.

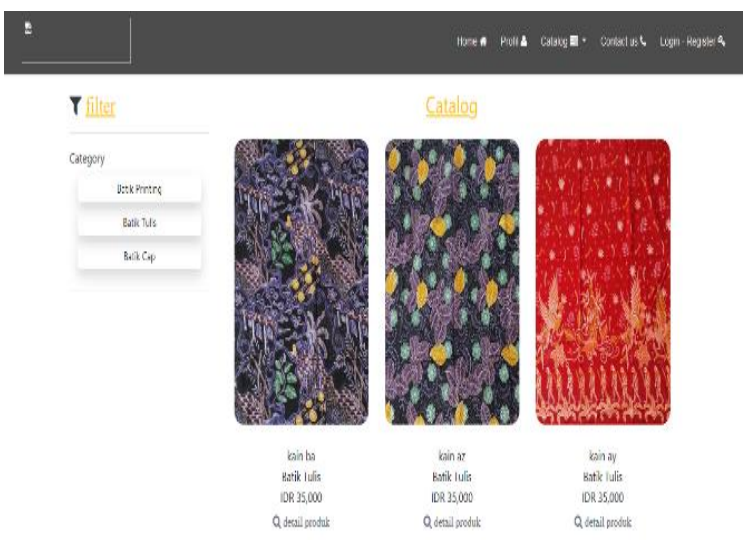

Gambar 4. Tampilan halaman katalog

\subsection{Tampilan Halaman Login}

Halaman login ditujukan untuk administrator, pelanggan, dan pemilik toko. Hak akses administrator dapat mengontrol semua data. Hak akses pelanggan diperlukan untuk melakukan transaksi. Pada saat yang sama, pemilik toko berhak menerima laporan dari semua data yang ada. Gambar tersebut adalah halaman login, seperti yang ditunjukkan pada Gambar 5 .

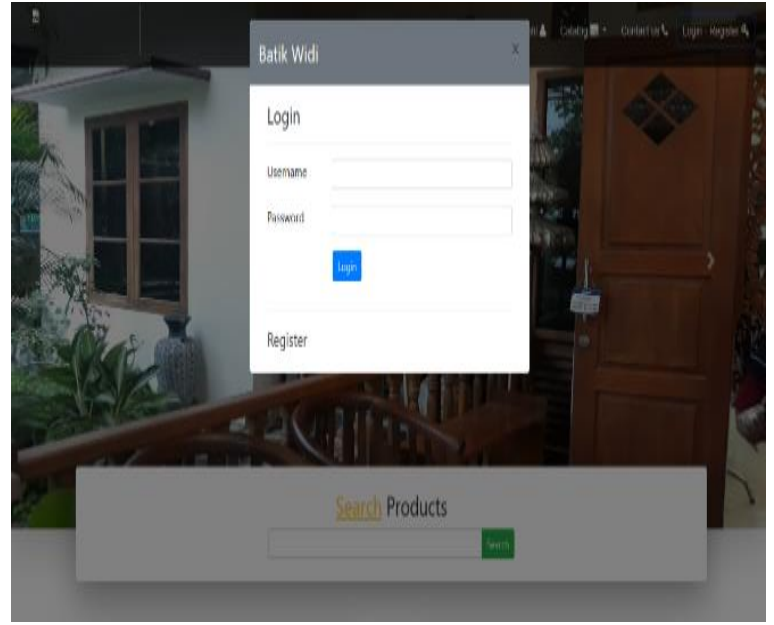

Gambar 5. Tampilan halaman login

\subsection{Tampilan Halaman Register}

Halaman registrasi ini digunakan untuk mendaftarkan pelanggan baru yang ingin bertransaksi. Gambar ini adalah halaman register, yang dapat dilihat pada Gambar 6.

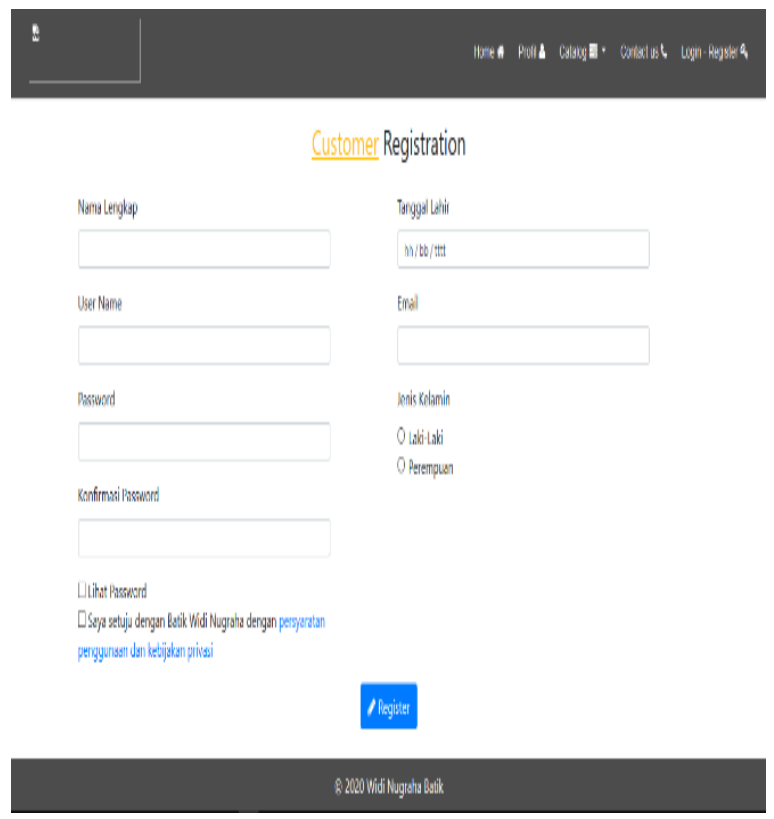

Gambar 6. Tampilan halaman register

\subsection{Pengujian Sistem}

Pada penelitian ini metode black box digunakan untuk menguji masukan dan keluaran yang dihasilkan oleh sistem informasi penjualan online berbasis web. Tujuan dari pengujian ini adalah untuk melihat apakah respon sistem informasi ini terhadap kasus uji sudah sesuai dengan harapan. Tabel 1 menunjukkan pengujian input yang dilakukan dengan menggunakan data input dalam sistem informasi penjualan online berbasis web. 
Tabel 1. Tabel Pengujian Masukan

\begin{tabular}{|c|c|c|c|}
\hline Kasus Uji & $\begin{array}{c}\text { Yang } \\
\text { Diharapkan }\end{array}$ & Pengamatan & $\begin{array}{c}\text { Kesimpula } \\
\mathbf{n}\end{array}$ \\
\hline $\begin{array}{l}\text { Memasukk } \\
\text { an data } \\
\text { Batik }\end{array}$ & $\begin{array}{l}\text { Mampu } \\
\text { menyimpan } \\
\text { data batik } \\
\text { sebagai } \\
\text { produk yang } \\
\text { dijual }\end{array}$ & $\begin{array}{l}\text { Data batik } \\
\text { tersimpan dan } \\
\text { dapat } \\
\text { ditampilkan }\end{array}$ & Sesuai \\
\hline $\begin{array}{l}\text { Memasukk } \\
\text { an data } \\
\text { pelanggan }\end{array}$ & $\begin{array}{l}\text { Mampu } \\
\text { menyimpan } \\
\text { data } \\
\text { pelanggan } \\
\text { sebagai } \\
\text { konsumen }\end{array}$ & $\begin{array}{l}\text { Data } \\
\text { Pelanggan } \\
\text { tersimpan dan } \\
\text { dapat } \\
\text { ditampilkan }\end{array}$ & Sesuai \\
\hline $\begin{array}{l}\text { Memasukk } \\
\text { an data } \\
\text { pemesanan }\end{array}$ & $\begin{array}{l}\text { Mampu } \\
\text { menyimpan } \\
\text { data } \\
\text { pemesanan }\end{array}$ & $\begin{array}{l}\text { Data } \\
\text { pemesanan } \\
\text { tersimpan dan } \\
\text { dapat } \\
\text { ditampilkan }\end{array}$ & Sesuai \\
\hline
\end{tabular}

Selain itu, data masukan diuji pada tampilan informasi atau keluaran yang dihasilkan oleh sistem informasi ini. Hasilnya berupa output dalam format file, termasuk soft copy (.pdf) dan hard copy (print output). Tabel 2 menunjukkan output hasil pengujian sistem informasi penjualan online berbasis web.

Tabel 2. Tabel Pengujian Keluaran

\begin{tabular}{|c|c|c|c|}
\hline Kasus Uji & $\begin{array}{c}\text { Yang } \\
\text { Diharapkan }\end{array}$ & Pengamatan & Kesimpulan \\
\hline $\begin{array}{l}\text { Tampilan } \\
\text { Daftar } \\
\text { Batik }\end{array}$ & $\begin{array}{l}\text { Ketika } \\
\text { memilih } \\
\text { tampilan } \\
\text { daftar batik, } \\
\text { maka akan } \\
\text { tampil data } \\
\text { batik. }\end{array}$ & $\begin{array}{l}\text { Data batik } \\
\text { tersimpan } \\
\text { dan dapat } \\
\text { ditampilkan }\end{array}$ & Sesuai \\
\hline $\begin{array}{l}\text { Tampilan } \\
\text { daftar } \\
\text { pelanggan }\end{array}$ & $\begin{array}{l}\text { Ketika } \\
\text { memilih } \\
\text { tampilan } \\
\text { daftar } \\
\text { pelanggan, } \\
\text { maka akan } \\
\text { tampil data } \\
\text { pelanggan }\end{array}$ & $\begin{array}{l}\text { Data } \\
\text { Pelanggan } \\
\text { tersimpan } \\
\text { dan dapat } \\
\text { ditampilkan }\end{array}$ & Sesuai \\
\hline $\begin{array}{l}\text { Tampilan } \\
\text { Data } \\
\text { pemesanan }\end{array}$ & $\begin{array}{l}\text { Mampu } \\
\text { menyimpan } \\
\text { data } \\
\text { pemesanan }\end{array}$ & $\begin{array}{l}\text { Data } \\
\text { pemesanan } \\
\text { tersimpan } \\
\text { dan dapat } \\
\text { ditampilkan } \\
\end{array}$ & Sesuai \\
\hline Kasus Uji & $\begin{array}{l}\text { Yang } \\
\text { Diharapkan }\end{array}$ & Pengamatan & Kesimpulan \\
\hline
\end{tabular}

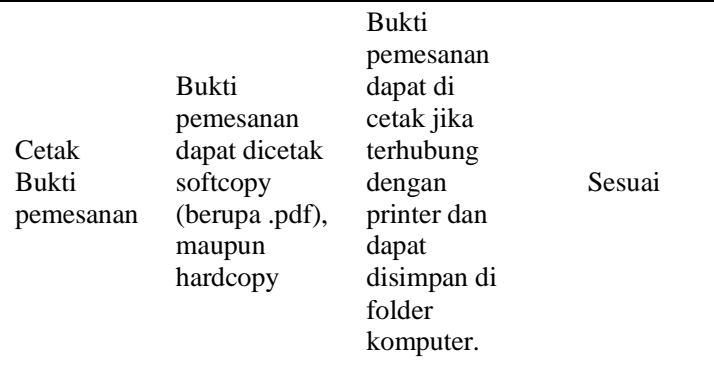

\section{KESIMPULAN}

Berdasarkan penelitian yang telah diselesaikan, dapat disimpulkan bahwa perancangan sistem informasi penjualan online berbasis web dapat membantu penjual dan pelanggan menggunakan media online untuk melakukan proses transaksi jual beli. Dengan sistem informasi penjualan online berbasis web akan dapat membantu mengurangi biaya distribusi. Sistem informasi berisi fungsi-fungsi yang mencakup informasi rinci tentang harga produk dan detail produk yang dijelaskan secara online. Dalam sistem informasi penjualan online, pelanggan tidak datang langsung ke toko, tetapi bisa membeli dari daerah manapun. Kesulitan dalam mengimplementasikan sistem informasi penjualan online berbasis web adalah masih banyaknya pembeli yang masih belum percaya dengan tingkat keamanan belanja online karena belum mendapat bantuan keamanan dari pemerintah dan kurang memahaminya.

\section{DAFTAR PUSTAKA}

[1] A. Saputra. 2017. "Analisis dan rekomendasi strategi e-commerce pada usaha kecil menengah batik sokaraja," J. Pro B isnis, vol. 10, no. 1, pp. 19-35.

[2] U. Mikro, K. Dan, M. Umkm, F. Irhamni, B. K. Khotimah, and B. D. Satoto. 2016. "SISTEM INFORMASI E-COMMERCE PRODUK UNGGULAN," vol. 2, no. 3, pp. 183-190.

[3] S. S. Laila Rahmawati,Kartika Imam Santoso. 2019. "E-COMMERCE PADA SENTRA BATIK TINGAL DI BOROBUDUR Penelitian dilakukan oleh Pratama dkk ( 2013 ) mengembangkan dengan metode RUP dan dibangun dengan bahasa pemrograman PHP dan untuk database menggunakan MySQL . Tujuan perancangan sistem informasi penjualan," vol. 15 , no. 1 , pp. 1-7.

[4] G. Wibisono and W. E. Susanto. 2015. "Perancangan Website Sebagai Media Informasi dan Promosi Batik Khas Kabupaten Kulonprogo," J. Evolusi, vol. 6, no. 2, pp. 4655.

[5] F. Amin, R. Soelistijadi, and A. Priambodo. 2012. "Aplikasi E-Commerce Sentra Batik di 
Kota Semarang Sebagai Salah Satu Upaya Media Promosi dan Transaksi Secara Online," Din. Teknol. Inf., vol. 17, no. 1, pp. 67-74.

[6] Irma Yunita. R and Lilis Suryani. 2018. "Perancangan e-commerce Batik Pada Batik Banten," J. Ilm. Sains Teknol. Univ. Banten Jaya Nufransa, vol. 5, no. 1, pp. 488-497, .

[7] I. G. S. Widharma. 2017. "Perancangan Simulasi Sistem Pendaftaran Kursus Berbasis Web Dengan Metode Sdlc," Matrix J. Manaj. Teknol. dan Inform., vol. 7, no. 2, p. 38. doi: 10.31940/matrix.v7i2.527.

[8] R. . Pressman. 2015. Rekayasa Perangkat Lunak: Pendekatan Praktisi Buku I. Yogyakarta: ANDI,.

[9] R.S. Pressman. 2005. Software Engineering, a practitioner's Approach. Mc Graw Hill, 6th edition,

[10] R. Rasyid, N. Amanah, and R. Adawiyah.2020. "Perancangan Sistem Informasi Perpustakaan Smkn 1 Loea Design Information System Library Smkn 1 Loea Kolaka Timur". JIKO(Jurnal Informatika dan Komputer), vol. 3, no. 2 , pp. $75-80$. 